\title{
Gestão das florestas degradadas, uma nova prioridade na Amazônia brasileira
}

\author{
Lilian BLANC - Joice FERREIRA - Marie-Gabrielle PIKETTY - Clément BOURGOIN \\ Valéry GOND - Bruno HÉRAULT - Milton KANASHIRO - François LAURENT \\ Marc PIRAUX - Ervan RUTISHAUSER - Plinio SIST
}

Na Amazônia brasileira, as florestas degradadas dominam as paisagens das frentes pioneiras. Atualmente, esta região enfrenta um grande desafio: parar a degradação e fazer a gestão sustentável dessas florestas. As florestas degradadas são atualmente parte integrante de uma categoria de florestas. No entanto, elas podem desempenhar um papel importante na luta contra as mudanças climáticas e podem contribuir para um melhor funcionamento ecológico dos territórios.
Desenvolver políticas públicas com o duplo objetivo de reduzir a degradação e melhorar a condição dessas florestas implica um forte apoio da pesquisa. Neste Perspective, nós focalizamos em quatro prioridades de pesquisa: desenvolver os métodos de caracterização e monitoramento das florestas degradadas, elaborar planos específicos de ordenamento do território, compreender o papel desempenhado por todos os atores sociais e acompanhar as politicas em escala territorial.
O impacto humano sobre as florestas amazônicas do Brasil não pode ser medido unicamente pelos indicadores de desmatamento. As florestas degradadas, caracterizadas pela destruição parcial do seu dossel, surgem atualmente como parte importante das florestas. Mesmo se o termo degradação florestal está sujeito a numerosos debates e compreende vários significados, as florestas degradadas representam bem uma realidade incontestável, quando avaliamos o papel que estes ecossistemas podem ter nas mudanças climáticas.

As medidas drásticas que permitiram ao Brasil reduzir a taxa anual de desmatamento da Amazônia de 27.770 km² em 2005 para 5.830 km² em 2015 não foram capazes de barrar a degradação das florestas. A política de luta contra o desmatamento foi implementada por um programa específico de prevenção e controle que engloba um conjunto de medidas iniciadas pelo governo federal, envolvendo 14 ministérios. Medidas repressivas proibiram a comercialização de produtos provenientes do desmatamento e impediram o acesso aos créditos rurais. Estas foram seguidas por iniciativas do setor privado (gado e soja principalmente), que reorganizaram a sua cadeia de produção, a fım de garantir produtos com "desmatamento zero".

A crescente conscientização por parte da comunidade científica sobre a importância das florestas degradadas nas paisagens amazônicas pode acompanhar uma mudança de paradigma em nível político. Lutar contra a degradação das florestas requer o desenvolvimento de medidas específicas de monitoramento, controle das atividades e melhoria dessas florestas. Tal como o que foi realizado com sucesso para controlar o desmatamento, um segundo passo deve ser visado, o da prevenção e controle da degradação florestal.

\section{A importância das florestas degradadas}

Na Amazônia brasileira, a simples divisão entre área florestada e desmatada, utilizada convencionalmente para mapear o estado da Amazônia, não reflete a realidade da situação florestal. As florestas degradadas são particularmente abundantes nas frentes pioneiras, regiões colonizadas desde 1960. Estas florestas são muito diferentes das florestas que não sofreram degradação. Nas regiões colonizadas, os recursos florestais (madeira, produtos florestais não-madeireiros e a fauna] foram amplamente retirados. Os recursos que foram retirados alteraram profundamente a estrutura e a função destas florestas: a biomassa é reduzida, a altura do dossel é mais baixa, a produtividade diminui, etc. As colheitas recorrentes impedem a reconstituição desses recursos. Além disso, essas florestas perderam a maior parte do seu potencial econômico e não fornecem mais os mesmos serviços ecossistêmicos (por exemplo, armazenamento de 
carbono e biodiversidade] que uma floresta primária ou floresta sob exploração sustentável.

Atualmente, as florestas degradadas dominam a paisagem florestal das regiões colonizadas. Por exemplo, no estado do Pará, o município de Paragominas faz parte dessas frentes pioneiras, colonizadas desde 1960 . Este municipio, que anteriormente se encontrava totalmente florestado, foi um polo regional de produção de madeira e posteriormente de produção de gado. Atualmente, as florestas cobrem apenas cerca de $50 \%$ da sua superfície. Os resultados estimados a partir do trabalho prévio da Rede Amazônia Sustentável e do projeto ECOTERA (ver caixa na página 4) mostraram que estas florestas residuais perderam 35 a $80 \%$ do seu estoque de carbono inicial.

Na Amazônia brasileira, a degradação florestal é um fenômeno generalizado. O programa de monitoramento, via programa DEGRAD desenvolvido pelo INPE (Instituto Nacional de Pesquisas Espaciais do Brasil) fornece dados desde a última década. Entre 2007 e 2012, 55.906 km² de floresta foram convertidos em pastagens e em terrenos agrícolas. Durante o mesmo período, quase o dobro desta superfície [102.923 km²] foi degradada.

Estes números realçam a urgência de considerar a degradação florestal como uma ameaça para a manutenção da integridade e funcionamento das florestas da Amazônia. Lutar contra esta degradação constitui, por um lado, uma prioridade ambiental para limitar a emissão de carbono para a atmosfera, relacionada com as mudanças climáticas, e por outro lado, para preservar a extraordinária biodiversidade desta região. É também uma prioridade social porque as florestas, mesmo que degradadas, são espaços de vida e de subsistência das populações rurais amazônicas.

Desenvolver políticas públicas, com o objetivo de diminuir a degradação das florestas e de melhorá-las, com o forte apoio da pesquisa, constitui um grande desafio na região amazônica para as próximas décadas. Para apoiar as decisões públicas e para implementar essas políticas públicas, propomos quatro prioridades de pesquisa.

\section{Prioridade $\mathrm{n}^{\circ} 1$. Desenvolver métodos e} indicadores para caracterizar a grande abrangência de florestas degradadas e a sua dinâmica na escala territorial

Nenhuma política de luta contra a degradação florestal pode ser eficaz se os impactos da degradação da floresta não puderem ser precisamente localizados e acompanhados ao longo do tempo. O programa PRODES (monitoramento do desmatamento via satélite, implementado pelo INPE], foi uma das chaves para o sucesso na luta contra o desmatamento. Atualmente é fácil medir o desmatamento através do monitoramento por satélite, mas ainda é muito difícil medir a destruição parcial da cobertura florestal.

A abertura parcial do dossel florestal, resultante do corte de uma ou mais árvores ou da passagem de um fogo, é um fenômeno transitório dificilmente detectável pelo monitoramento via satélite. A vegetação recoloniza estas aberturas mais ou menos rapidamente, dependendo das condições do solo e da vegetação circundante e, em poucos meses, a abertura do dossel florestal pode se tornar indetectável nas imagens de satélite.

Uma análise temporal é essencial para identificar, em espaços de tempo regulares e frequentes, cada episódio de degradação. A acumulação ao longo do tempo das áreas afetadas por esses episódios de degradação permite conhecer a área superficial das florestas degradadas, para um período e região específicos. A análise temporal consiste, em primeiro lugar, em desenvolver algoritmos para identificar pequenas superfícies de impacto e também para ter imagens de satélite frequentes e de qualidade (sem nuvens]. Estas dificuldades explicam as diferenças nos resultados, por vezes em um fator de até três vezes, dependendo do ano, fornecidos por dois programas de estimativa das áreas florestais degradadas - programa DEGRAD do INPE e a organização não-governamental Imazon.

Até agora, a frequência e a resolução espacial das imagens disponiveis eram um fator limitante para uma medição suficientemente precisa no tempo e no espaço. Esta limitação poderá ser parcialmente eliminada graças à disponibilidade,

\section{Floresta degradada perto de $>$ um campo de soja no município de Paragominas}

As florestas degradadas são caracterizadas pela destruição

parcial do seu dossel. Estas dominam a paisagem florestal das regiões colonizadas na Amazônia. Atualmente, proteger as florestas

contra novos eventos de degradação e melhorá-las com planos de manejo inovadores constituem uma prioridade. Foto () V. Gond

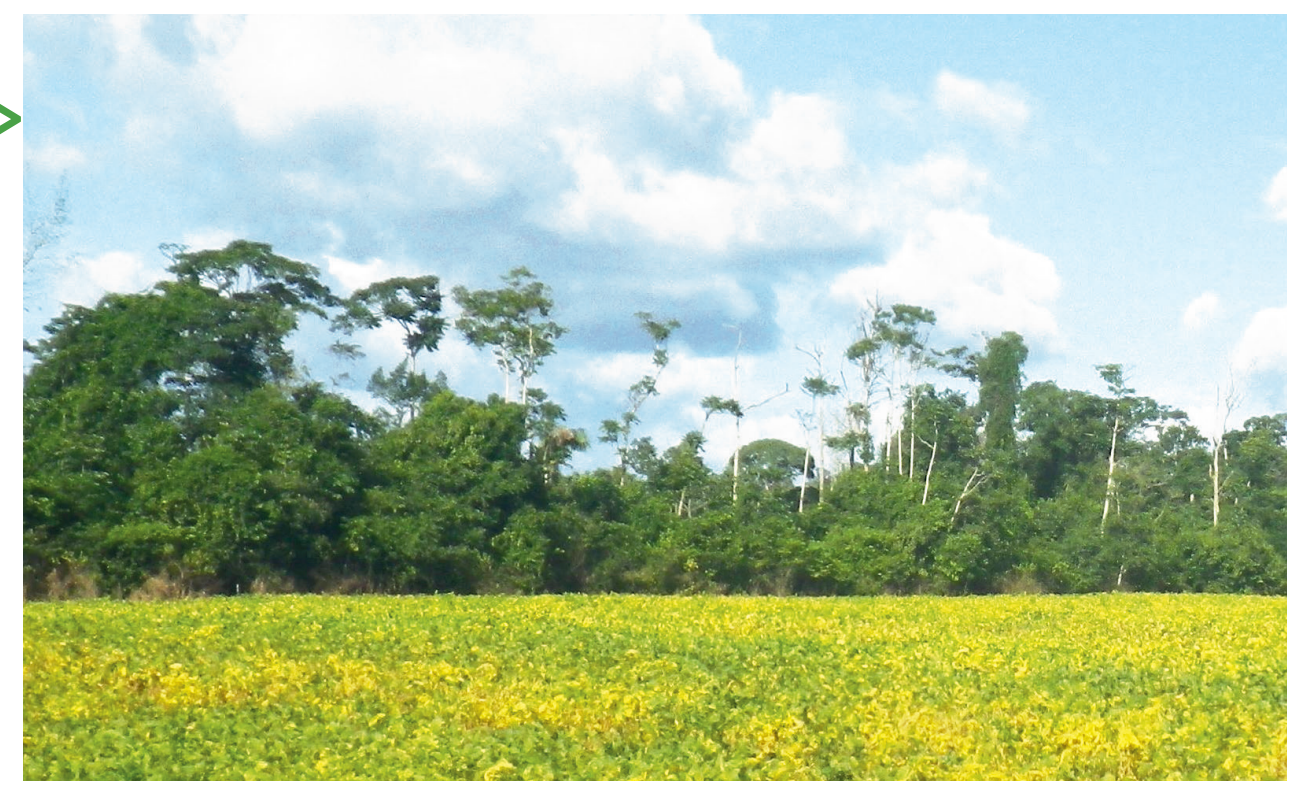


desde 2016, de imagens de resolução espacial alta e muito alta de satélites de observação da Terra da Agência Espacial Europeia, SENTINEL-1 e SENTINEL-2.

Uma solução alternativa é avaliar o estado da floresta através da medição do estoque de carbono, revelador de impactos passados. 0 sensoriamento remoto laser [Lidar] ou radar é promissor e tem a vantagem de não ser perturbado pela presença de nuvens, ao contrário das imagens óticas. Atualmente não existe nenhum sensor de satélite deste tipo capaz de fornecer uma estimativa na escala da Amazônia. Mas, a partir de 2020, um satélite radar fornecerá dados sobre a estrutura da floresta em três dimensões e sobre a sua biomassa à escala mundial — programa BIOMASS da Agência Espacial Europeia e do Centro Nacional de Estudos Espaciais Francês.

\section{Prioridade $\mathrm{n}^{\circ} 2$. Elaborar planos de manejo adaptados às florestas degradadas}

O modelo de plano de manejo implementado na Amazônia brasileira não é adequado para florestas degradadas. Este modelo consiste em remover algumas árvores (uma parte da madeira explorável) numa área definida e na qual não haverá nenhuma exploração durante um período de 35 anos de forma a permitir que a floresta reconstitua o seu volume em madeira. A madeira explorável residual e as árvores comerciais pequenas formam, assim, a futura colheita. As florestas degradadas perderam todo ou parte deste potencial, porque até mesmo as árvores com um diâmetro inferior a 60 ou 70 centímetros foram exploradas. Estas florestas não podem reconstituir em menos de 35 anos um volume de madeira explorável, mas elas podem manter a capacidade de reconstitução: isto foi revelado por um estudo recente realizado pela rede TmFO (Tropical managed Forests Observatory, ver caixa na página 4].

O estudo da rede TmFO mostra que as florestas amazônicas sob manejo mantêm a sua capacidade de reconstituir carbono a depender da intensidade de exploração. Este estudo mostra também que o tempo de reconstituição do carbono depende principalmente dessa intensidade. Assim, uma floresta sujeita a uma exploração moderada de madeira, equivalente a $10-20 \%$ do seu estoque de carbono inicial, reconstituirá esse estoque em menos de 25 anos: é o caso das florestas geridas com um plano de manejo. No entanto, uma floresta submetida a uma colheita de 50 a $60 \%$ do seu estoque de carbono inicial, porcentagem frequentemente registrada no caso das florestas degradadas, necessita até 75 anos para o repor. A condição indispensavél para permitir essa reposição é que nenhuma colheita seja realizada durante esse período. Além disso, as florestas devem ficar livres de outros fatores importantes de degradação como as queimadas.

Este estudo mostra também que a capacidade de reconstituição do carbono é a mesma em toda a Amazônia: quer estejam perto da costa do Atlântico ou no sopé dos Andes, as florestas amazônicas sob planos de manejo têm o mesmo potencial de reconstituição, predito principalmente pela intensidade de exploração.

Estes resultados constituem mais informação para desenvolver planos de manejo adaptados à diversidade de flores- tas degradadas. Esses planos poderão integrar igualmente intervenções silvícolas particulares para acelerar a restauração dessas florestas. As ações podem consistir em enriquecer o povoamento florestal com espécies arbóreas de interesse comercial, ou realizar desbaste seletivo para promover o crescimento das árvores jovens. Esta silvicultura poderia ter como alvo tanto a madeira como os produtos florestais não madeireiros, por exemplo, castanha do Brasil, frutos da palmeira, óleos e resinas.

\section{Prioridade $\mathrm{n}^{\circ} 3$. Compreender o papel desempenhado por todos os atores sociais na degradação florestal}

Os estudos científicos até o momento focaram principalmente nos impactos ecológicos da degradação: estes deveriam expandir-se para envolver múltiplos aspectos, incluindo as diversas disciplinas do conhecimento, em particular as ciências sociais. Os agentes da degradação, envolvidos em muitos jogos de alianças e conflitos, são de fato numerosos e variam de um território para o outro. Por exemplo, as populações locais pobres, principalmente agrícolas, beneficiam das colheitas da floresta - caça, madeira para construção, venda ou fabricação de carvão vegetal. A análise das suas práticas florestais e agrícolas permitiria identificar 0 lugar e o valor que representa a floresta para estas populações, em termos econômicos e sociais.

Estes conhecimentos servirão para desenvolver propostas técnicas e econômicas mais adaptadas às populações locais, bem como regras individuais e coletivas de gestão dos recursos florestais compreendidas e aceitas por cada um dos atores envolvidos. Algumas propostas, que visam ajudar sobretudo a agricultura familiar e que incluem um manejo florestal comunitário, poderiam ser a base concreta de uma política orientada para as populações pobres e tornarem as políticas públicas de luta contra a degradação florestal mais eficazes. Outras propostas poderiam favorecer a participação dos atores sociais das frentes pioneiras para melhorarem e conservarem os seus ecossistemas florestais.

\section{Prioridade $\mathrm{n}^{\circ} \mathbf{4}$. Acompanhar as políticas do município em escala territorial para garantir paisagens multifuncionais sustentáveis}

O município é uma escala de território pertinente para a gestão multifuncional, enquanto as ações públicas e privadas nesta área são ainda poucos articuladas. A transição para uma abordagem territorial permitiria mudar as práticas de manejo e técnicas, renovar as relações entre atores e, finalmente, iniciar novos modos de gestão.

Para fazer emergir essas novas regras e acompanhar esta transição, o papel da pesquisa é criar ferramentas baseadas no acompanhamento e na modelagem participativa. Estas ferramentas têm como objetivo desenvolver uma visão territorial e ajudar a regular as transformações territoriais quando as escolhas individuais têm repercussões sobre todo o espaço em questão. Tomemos como exemplo o código florestal brasileiro: atualmente, este exige que cada proprietário conserve uma reserva florestal que varia entre 50 e $80 \%$ da área total da sua propriedade, além disso, 
deve incluir obrigatoriamente áreas de proteção permanente (margens de rios e encostas). Em alguns casos, isto causa uma grande fragmentação da cobertura florestal. Estes fragmentos florestais encontram-se muitas vezes extremamente degradados, muito vulneráveis a incêndios e sujeitos à expansão agrícola; e estão condenados a desaparecer no futuro. Como tal, a aplicação do código em escala da propriedade não garante uma paisagem florestal multifuncional e sustentável em escala territorial. A pesquisa poderia ajudar a expandir as regras do código florestal, principalmente em relação à propriedade privada, no sentido de uma aplicação mais ampla, em nível do território.

Para concluir, reconhecer que a degradação florestal representa uma ameaça grave para a conservação dos recursos naturais da Amazônia é uma prioridade para os cientistas. Este reconhecimento requer também a mobilização da sociedade civil e dos tomadores de decisão, à imagem das suas implicações nos programas de luta contra o desmatamento na Amazônia.

Este Perspective n $^{\circ} 40$ é o resultado dos trabalhos de pesquisa realizados no seio do dispositivo de investigação e educação em parceria "Florestas, agricultura e territórios na Amazônia" [www.dp-amazonie.org/], no âmbito de diferentes projetos:

- projeto ECOTERA [ECOefficiences et développement TERritorial en Amazonie Brésilienne, ANR-13-AGRO-0003, www.agencenationale-recherche.fr/?Projet=ANR-13-AGRO-0003] financiado pela ANR (Agence nationale de la recherche);

- rede TmFO [Tropical managed Forests Observatory, www.tmfo. org/] criada em 2012 pelo Cirad no âmbito do programa de pesquisa FTA [Forest Trees and Agroforestry, http://foreststreesagroforestry.org/] do CGIAR [Consultative Group on International Agricultural Research, www.cgiar.org/];

- rede RAS, Rede Amazônia Sustentável, www.redeamazoniasustentavel.org/].

Sobre o tema das florestas degradadas nos trópicos úmidos, este trabalho resultou em particular nas seguintes publicações:

Berenguer E., Ferreira J., Gardner T.A., Aragão L. E.O.C., De Carmargo, P.B., Cerri C.E., Durigan M., Oliveira R.C.D., Vieira I. C.G., Barlow J.A., 2014. A large-scale field assessment of carbon stocks in human-modified tropical forests. Global Change Biology 20 (12): 3713-3726. http://dx.doi.org/10.1111/gcb.12627.

\section{Algumas palavras sobre...}

Lilian BLANC (lilian.blanc@cirad.fr) e Plinio SIST (plinio.sist@cirad.fr) são ecólogos florestais no Cirad, UPR Florestas \& Sociedades (http://ur-foretssocietes.cirad.fr/], Montpellier, França.

Joice FERREIRA (joice.ferreira@embrapa.br) é bióloga e Milton KANASHIRO (milton.kanashiro@embrapa.br) é engenheiro florestal na Embrapa (Empresa Brasileira de Pesquisa Agropecuária, www.embrapa.br/], Belém, Brasil.

Marie-Gabrielle PIKETTY (marie-gabrielle.piketty@cirad.fr) é economista no Cirad, UPR GREEN (Gestão de Recursos Renováveis e Meio Ambiente, http://ur-green.cirad.fr/], Montpellier, França.

Clément BOURGOIN (clement.bourgoin@cirad.fr) e Valéry GOND (valery.gond@cirad.fr) são geógrafos que trabalham com sensoriamento remoto no Cirad, UPR Florestas \& Sociedades (http://ur-forets-societes. cirad.fr/], Montpellier, França.

Bruno HÉRAULT (bruno.herault@cirad.fr) é um ecólogo que trabalha em modelagem no Cirad, UMR EcoFoC (Ecologia das florestas da Guiana, www.ecofog.gf/], Kourou, Guiana Francesa.

François LAURENT é professor de geografia na UMR Espaços e Sociedades, laboratório ESO Le Mans (http://eso-lemans.cnrs.fr/), Universidade de Maine, Le Mans, França.

(c) Esta obra está disponível (C) (1) (2) sob os termos da licença reative Commons CC-BYNC-SA 4.0: Atribuição - Uso Não Comercial Partilha nas mesmas condições - 4.0 Internacional https://creativecomm na-sa/4.0//deed pt BR
Para citar este documento

Blanc L., Ferreira J., Piketty M.C., Bourgoin C. Gond V., Hérault B., Kanashiro M., Laurent F. Piraux M, Rutishauser E, Sist P. 2017. Gesta das florestas degradadas, uma nova prioridade na Amazônia brasileira. Cirad, Montpellier Perspective 40

http://dx.doi.org/10.18167/agritrop/00042.
Blanc L., Gond V., Ho Tong Minh D., 2016. Remote sensing and measuring deforestation. In: Baghdadi N., Zribi M. [Eds] Land surfaces Remote sensing: Environment and risks. Londres, ISTE Press-Elsevier, pp. 27-53. ISBN 978-1-78548-105-5.

Bourgoin C., Baghdadi N., Blanc L., Ferreira J., Gond V., Mazzei L., Oswald J., 2015. Identifying classes of degraded forests in an Amazonian Landscape frm remote-sensing. Comunicação no $27^{\circ}$ International Congress for Conservation Biology, Society for Conservation Biology, 2-6 Agosto 2015, Montpellier, França. http://agritrop.cirad.fr/581815/.

Ferreira J., Blanc L., Kanashiro M., Lees A.C., Bourgoin C., de Freitas J.V., Gama M.B., Laurent F., Martins M.B., Moura N., d`Oliveira M.V., Sotta E.D., de Souza C.R., Ruschel A.R., Schwartz G., Zwerts J., Sist P., 2015. Degradação florestal na Amazônia: a urgência de ultrapassar barreiras conceituais, científicas e técnicas para orientar a gestão e conservação das florestas. Embrapa Amazônia Oriental, Bélem, Documentos 413, 29 p., ISSN 19830513. www.infoteca.cnptia.embrapa.br/handle/doc/1027698.

Rutishauser E., Hérault B., Baraloto C., Blanc L., Descroix L., Doff Sotta E., Ferreira J., Kanashiro M., Mazzei L., Oliveira M.V.N., de Oliveira L.C., Peña-Claros M., Putz F.E., Ruschel A.R., Rodney K., Roopsind A., Shenkin A., da Silva K.E., de Souza C.R., Toledo M., Vidal E., West T.A.P., Wortel V., Sist P., 2015. Rapid tree carbon recovery in Amazonian logged forests. Current Biology 25 (18): R787-R788. http://dx.doi.org/10.1016/j.cub.2015.07.034.

Marc PIRAUX (marc.piraux@cirad.fr) é geógrafo no Cirad, UMR TETIS (Territórios, Meio Ambiente, Sensoriamento Remoto e Informação Espacial, www.tetis.teledetection.fr), Belém, Brasil.

Ervan RUTISHAUSER (er.rutishauser@gmail.com) é ecólogo florestal na empresa CarboFor-Expert (http://carboforexpert.ch/], Genebra, Suiça.

\section{Alguns links}

Centro nacional de estudos espaciais (National Centre for Space Studies, CNES, França]. BIOMASS, um satélite para monitorizar as florestas https://biomass.cnes.fr/en/BIOMASS/index.htm European Space Agency [ESA], SENTINEL Missions. https://sentinel.esa.int/web/sentinel/missions Imazon. http://imazon.org.br/ Instituto Nacional de Pesquisas Espaciais (INPE, Brasil). www.inpe.br/

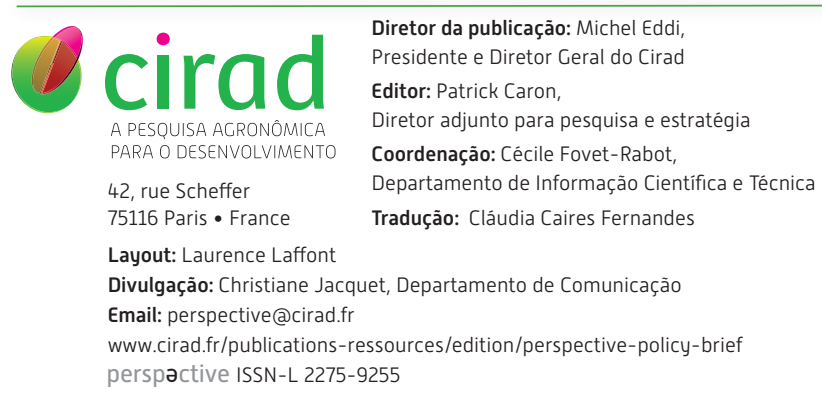

